\title{
Distinguishing white-tailed bumblebees in the Netherlands: morphology, ecology and DNA-barcoding
}

\author{
Lucas Alferink $^{1}$, Leon Marshall ${ }^{1}$, Roland De Jonghe ${ }^{2}$, and Jacobus Biesmeijer ${ }^{1}$ \\ ${ }^{1}$ Naturalis Biodiversity Center \\ ${ }^{2}$ Affiliation not available
}

September 10, 2020

\begin{abstract}
White-tailed bumblebee species, Bombus cryptarum, B. lucorum, B. magnus and B. terrestris are known to be very similar in their morphological characters across the majority of their ranges. This hampers assessment of their status and trends because reliable identification is difficult. In this study, we use a combination of characters and methods to assess how ecologists and citizen scientists can reliably and quickly separate these four species occurring in the Netherlands. Bumblebees (queens, workers and males) were sampled from 10 locations across the Netherlands and specimens were identified based on COI sequence data. Next, the same specimens where scored for morphological traits. We show that a combination of easy to recognise characteristics can separate some specimens of the species depending on caste and sex. Bombus magnus males and queens and B. lucorum males were most reliably separated from the other species using morphological characters. Workers of all four species cannot be separated completely using morphological characters alone. This is the first time standard morphological characters and ecological data has been used to study the differences between the white-tailed bumblebees in the Netherlands. Based on our findings we need to conclude that the status of these bumblebee species in the Netherlands is uncertain due to possible misidentifications in the past and present. People who wish to work with these species should be careful in species identification based on morphology.
\end{abstract}

\section{Concise cover letter}

We attempt to answer the question if easily recognizable characteristics can be used by non-experts to reliably identify bumblebees of thelucorum complex and Bombus terrestris in the Netherlands.

\section{Introduction}

Bumblebees are one of the most important groups of pollinators, both in their natural environment as well as in the pollination of crops (Velthuis and Doorn, 2006). Due to their ecological significance, the necessity to conserve them is high, but in order to do so it is vital to understand the distribution ranges of separate species, as bumblebee species have different habitat requirements and respond differently to environmental stressors (Goulson et al., 2008; Marshall et al., 2018). Over the last century, bumblebees have declined in abundance and richness in Western Europe (Biesmeijer et al. 2006; Carvalheiro et al. 2013) and North America (Cameron et al. 2011), due to habitat loss and a decrease in floral resources (Goulson et al. 2008). Data from the Netherlands predicts a 19\% decrease in bumblebee species richness from 1945 to 2018 (van Dooren et al. 2019). To understand changing patterns in biodiversity and its significance to agriculture and society, it is essential that species are correctly identified. However, the difficulty with species identification in bumblebees is that many share a similar morphology. In the Netherlands the most difficult species to identify belong to the subgenus Bombus sensu stricto, namely Bombus terrestris, B. cryptarum, B. lucorum and B. magnus, the latter three being the lucorum complex. They are cryptic species, separate species which are difficult to distinguish by morphology. In the past, these three species were grouped under the name $B$. 
lucorum . However, blends of male labial gland secretions (Bertsch et al. 1997; Bertsch et al. 2004; Bertsch et al. 2005), together with DNA sequencing of the mitochondrial COI gene (Pedersen, 2002; Bertsch et al. 2005; Murray et al. 2008), revealed that B. cryptarum, B. lucorum and B. magnus were distinct species. In addition, interbreeding experiments have resulted in no offspring (De Jonghe and Rasmont, 1983), confirming that they are separate species. Bombus terrestris is another white-tailed bumblebee from the subgenus Bombus sensu stricto . On continental Europe, the subspecies B. terrestris terrestris occurs (Rasmont et al. 2013), of which the different castes and sexes are morphologically similar to those of the lucorum complex species (Wolf et al. 2010; Bossert, 2015).

In the past, many different characters have been used to distinguish thelucorum complex species. The key features often used are the colour patterns in the collar of queens, such as an S-shape line of black hairs and the extent of the yellow collar downwards (Figure 1; Rasmont, 1984; Bertsch et al. 2004; Bertsch et al. 2005; Carolan et al. 2012). These characteristics can be helpful in species identification, but are hampered by overlap between species and geographic variation within species (Bertsch et al. 2004; Bertsch et al. 2005; Carolan et al. 2012). Waters et al. (2011) assessed the extension of the yellow collar in workers of the lucorum complex in the Western Isles of Scotland. Although they found that this character can be diagnostic for $B$. lucorum and B. magnus, there was much variation and $B$. cryptarum was not properly distinguishable from the other two species. According to Murray et al. (2008) Irish workers of thelucorum complex are morphologically indistinguishable in the field.

Most authors agree that males of the lucorum complex are either morphologically indistinguishable (Waters et al. 2011; Murray et al. 2008) or that identifications based on morphology are unreliable (Bertsch, 2009). Male genitalia are identical for the species of the complex (Rasmont et al. 1986). Characters used to identify males are often based on the colour of the facial hair (Rasmont et al. 1986), but the reliability of these characters has not been tested so far.

Problems with morphological identification have not refrained authors to draw conclusions on the distribution of the individual species. For example, Bombus lucorum is considered widespread and abundant across Europe (Banaszak and Rasmont 1994; Urbanová et al. 2001; Murray et al. 2008; Vesterlund et al. 2014; Scriven et al. 2015; Bossert et al. 2016) as is B. terrestris (Banaszak and Rasmont 1994; Peeters et al. 2012; Bossert et al. 2016). DNA-based studies in Great-Britain and Ireland (Murray et al. 2008; Waters et al. 2011; Scriven et al. 2015) have shown that species of the lucorum complex co-occur at many sites and that much of their distribution overlaps. In addition,Bombus lucorum, B. terrestris and B. cryptarum are polylectic in the British Isles (they visit plant species from multiple plant families; Waters et al. 2011; Scriven et al. 2015), although in the Western Isles of Scotland B. lucorum was observed mostly feeding on Ericaceae and Apiaceae (Waters et al. 2011). Bombus magnus was found to be associated with heather, in particular with Calluna vulgaris (Waters et al. 2011; Scriven et al. 2015; Scriven et al. 2016), Erica cinerea (Scriven et al. 2015; Scriven et al. 2016) and Erica tetralix (Scriven et al. 2015; Scriven et al. 2016).

The difficulty in separating these four bumblebee species has important consequences for studies investigating distribution and ecology. The chances of misidentification are high and can result in cascading effects which ultimately may lead to incorrect conclusions regarding ecosystem functioning and species trends over time (Bortolus, 2008). For example, many misidentifications occur in natural history collections (Bertsch, 2009) and these historical records are often used in studies regarding long-term species trends, leading to incorrect outcomes. Many of these species are also regularly reported on citizen science websites and in ecological scientific studies and due to the different ecology of the species it then is important to make an accurate distinction.

In this study, the goal was to investigate to what extent easily recognizable characteristics can be used by non-experts to reliably identify species of the lucorum complex and B. terrestrisin the Netherlands. We expected that these four white-tailed bumblebee species are similar in most of their morphology as they are in other parts of continental Europe. We hypothesise that reliable identification will only be possible for all four species using COI sequences. 


\section{Materials and Methods}

In total, 287 specimens were sampled from nine different locations across the Netherlands and one in Belgium (Table 1) between April-August, 2017. The ten sample locations were selected because of the likely occurrence of all four species in many of these sites based on historical collection data (that may have been identified incorrectly, but were used as a starting point). Bumblebees were sampled randomly with an insect net or collection tube from 10:30 am until 04:00 pm at each site. A further 152 bumblebees from 13 self-bred colonies (containing B. cryptarum , B. lucorum , B. terrestrisand B. magnus ) were added to the study (Table 2), because more individuals of especially B. magnus were needed. Two bumblebees collected from a box of $B$. terrestris marketed for crop pollination by Koppert Biological Systems were also added to the dataset (Table 2), because some of them showed the S-shape line, which is described as a characteristic for B. cryptarum queens (Rasmont, 1984; Bertsch et al. 2004; Bertsch et al. 2005; Carolan et al. 2012), while they are claimed to be the subspecies B. terrestris dalmatinus. This resulted in a total of 451 individual bumblebees. The number of specimens that was used in the different analyses is lower, because only a DNA sample was taken from spring queens in the field in order to not to disturb the establishment of new colonies. Only one specimen from each self-bred colony was sequenced, because this allowed assignment of the whole colony to species level.

\section{Morphology analysis}

Both qualitative and quantitative characters were used in this analysis. Some of the qualitative characters have previously been used to distinguish queens of the four species (Rasmont, 1984; Bertsch et al. 2004; Bertsch et al. 2005; Bertsch, 2009; Carolan et al. 2012). Other qualitative characters are associated with the males, such as facial hair colour. An overview of the colour characteristics used by Rasmont to separate the males of the lucorum complex and B. terrestris can be found in Table 3. We did not look at characters that need examination with a stereomicroscope, such as the absence of punctures and microsculpture on the hind margin of tergite 2 to distinguish B. terrestris queens from the other species (Rasmont, 1984; Amiet, 1996), because we wanted to test to what extent easily recognizable characteristics can be used by non-experts. The following morphological characters have been included in the analysis: S-shape right and S-shape left (ssr, ssl; Figure 1A), melanisation of the collar (mc; Figure 1B), extension of the collar right and extension of the collar left (ecr, ecl; Figure 1C), brown-yellow bands (byb; Figure 1D), yellow hairs on scutellum (yhs; Figure 1E), yellow facial hair (yh; Figure 2B) and yellow moustache (ym; Figure 2C). The character "brown-yellow bands" was included because this coloration of the collar and tergite 2 is often associated with $B$. terrestris (see Figure 1; Peeters et al. 2012; Falk, 2017). An overview with photographs of the qualitative characteristics used in this analysis can be seen in Figures 1 and 2.

The quantitative characters were measured on each individual by using Axiovision x64 version 4.9.0.0. Focus was given to measurements concerning the yellow collar. The following measurements have been included in the analysis: intertegular distance (the length between the bases of the wings, a proxy for body size; itd; Figure 2D), collar breadth dorsal side (cb; Figure 2D), length of collar below tegula right (lcr; Figure $2 \mathrm{E}$ ), breadth of collar below tegula right (bcr; Figure 2E), length of collar below tegula left (lcl; Figure 2F) and breadth of collar below tegula left (bcl; Figure 2F). An overview of the measurements included with photographs is provided in Figure 2. Photographs in Figure 1 and 2 were made with a Zeiss Discovery.v20 Photomicroscope and Axiovision x64 version 4.9.0.0 software and flipped, so that images from both the right and left side were comparable. Figure 1 and 2 were made in Adobe Photoshop CS6 (version 13.0; 1990-2012 Adobe Systems Incorporated). The same person took all measurements.

In total 337 specimens (39 queens, 201 workers and 97 males) were included in this analysis. Caste and sex were analysed separately because of the morphological differences between the sexes. Principle component analyses (PCAs) were carried out in order to visualize the variation among the specimens and to see if specimens from the same species are clustered together due to certain morphological characteristics. The qualitative characteristics were also analysed with a chi-square test to see which characters had a positive relation to certain species. Quantitative characteristics were analysed with a one-way ANOVA test and pairwise comparisons, with either Tukey HSD test or Wilcoxon rank sum test and were performed to see 
if species differ significantly based on certain quantitative characters. Boxplots were made to visualize the difference in quantitative characteristics and residual plots were made to show the relationship between qualitative characteristics and species. All analyses were performed in $R$ and RStudio ( $R$ version 3.4 .2 and RStudio version 1.1.383; R Core Team, 2017).

\section{DNA sequencing}

In order to correctly identify the specimens to species level DNA sequencing was used. Sequencing was done after morphological characteristics were measured to remove any bias. The gene that was sequenced is the cytochrome c oxidase subunit I (COI), which in bumblebees has been used to separate morphologically identical species (Williams et al. 2012) and has been used in many studies concerning the four white-tailed bumblebees (Pedersen, 2002; Bertsch et al. 2005; Murray et al. 2008; Waters et al. 2011; Carolan et al. 2012; Scriven et al. 2015; Bossert et al. 2016).

Of 346 specimens the pretarsus and part of the tarsus were taken for DNA extraction. Spring queens were put in queen marking tubes in order to extract a tarsus in the field. The tarsi were put in $200 \mu \mathrm{l}$ T1-Lysis buffer and a scalpel was used to cut the tarsi in several pieces so that the DNA was accessible. Twenty-five $\mu l$ Proteinase $\mathrm{K}$ was added to each sample and extraction was done according to a standard protocol with the use of a KingFisher DNA extraction robot, program: Machery_Nagel_Tissue_96 KingFisher Flex. Polymerase chain reactions (PCRs) were performed by using the universal primers LCO1490 and HC02198 (Folmer et al. 1994) with each a pipetting volume of $1,00 \mu \mathrm{l}(10 \mathrm{pMol} / \mu \mathrm{l})$ per sample. The PCR mix per sample further contained 18,8 $\mu \mathrm{l} \mathrm{mQ}$ (Ultrapure), 2,50 $\mu \mathrm{l}$ buffer CL (10x) (Qiagen), 0,50 $\mu \mathrm{l}$ dNTP $(2,50 \mathrm{mM}), 0,25 \mu \mathrm{l}$ Taq polymerase $(5,00 \mathrm{U} / \mu \mathrm{l})$ (Qiagen) and 1,00 $\mu$ l template DNA, resulting in a total volume of 25,0 $\mu \mathrm{l}$. The PCR program was perfomed with a Bio-Rad C1000 Touch ${ }^{\mathrm{TM}}$ Thermal Cycler and consisted of initial denature at $94^{\circ} \mathrm{C}$ for 3 minutes, followed by 40 cycles of denature at $94^{\circ} \mathrm{C}$ for $15 \mathrm{~s}$, annealing at $50^{\circ} \mathrm{C}$ for $30 \mathrm{~s}$ and extension at $72^{\circ} \mathrm{C}$ for 40 s. Final extension was performed at $72^{\circ} \mathrm{C}$ for 5 minutes followed by an infinite pause at $12^{\circ} \mathrm{C}$. To estimate the success of the PCRs, $3 \mu$ of each PCR product was run on a 96 Agarose Gel, $2 \%$ (E-Gel@). Photograph of the gel was taken with a Red ${ }^{\mathrm{TM}}$ Imaging System (Cell Biosciences) and edited by using E-Editor ${ }^{\mathrm{TM}}$ version 2.0.2. Successful PCR products were sent to BaseClear (BaseClear B.V. Leiden)

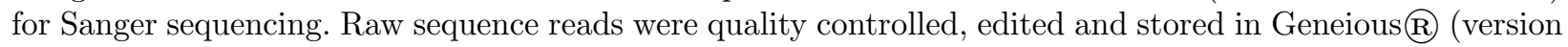
8.1.8; 2005-2015 Biomatters Ltd). Alignment was done with the plugin MAFFT Multiple Alignment version 1.3.3. Edited reads were exported as FASTA files and compared with the NCBI GenBank BLAST page (Altschul et al. 1990) to identify the individual reads. Specimens which were not successfully sequenced were excluded from further analyses. A maximum likelihood tree was made in Geneious $\mathbb{R}$ by using the plugin PHYML (Guindon and Gascuel, 2003) and edited in FigTree (version 1.4.3; Rambaut, 2006-2016). The bee Macropis europaea was added as outgroup (Schmidt et al. 2015; GenBank accession number: KJ839299.1). The tree was modified in Adobe Illustrator CS6 (version 16.0.0; 1987-2012 Adobe Systems Incorporated).

\section{Results}

The residual plot of the qualitative characteristics shows a strong positive relationship between B. magnus and the extension of the yellow collar and to a lesser extent a positive relationship between $B$. cryptarum and the S-shape line (Figure 3). This is in agreement with the presence/absence scores of the qualitative characteristics (Table 4). Almost all queens of B. cryptarum show the presence of an S-shape (11/12) and all queens of B. magnusshow extension of the yellow collar (4/4).

The results from the pairwise comparisons of the quantitative characters show that in queens, $B$. terrestris has a significantly larger intertegular distance compared to B. cryptarum (0.01[?]p[?]0.001, Table 5; Figure 4). However, there was overlap between all species within this characteristic. Bombus cryptarum also has a significantly smaller breadth of the yellow collar at the dorsal side than the other three species $(\mathrm{p}<0.001$, Table 5; Figure 4).Bombus magnus has a significantly longer yellow collar below the tegula on both the right and left side compared to the other species $(\mathrm{p}<0.001$, Table 5; Figure 4). There were no significant differences in the breadth of the collar below the tegula on both the right and left side and there was much overlap within these characteristics (Table 5; Figure 4). 
In workers, the residual plot shows again a strong positive relation between B. magnus and the extension of the collar but also a negative relation with brown-yellow bands (Figure 5). Bombus cryptarum shows positive relations with the S-shape line as well as with melanisation of the collar (Figure 5). Bombus terrestris has a positive relation with brown-yellow bands and a negative relation with the extension of the collar (Figure 5). On the contrary, the presence/absence data shows that only 25/41 of B. magnus workers have extension of the collar (Table 4 ). In B. cryptarum, only $3 / 10$ of the workers show the S-shape and $1 / 10$ show melanisation (Table 4).

Results from the pairwise comparisons show that in workers, B. terrestris and B. lucorum have significantly larger intertegular distances than B. cryptarum and B. magnus respectively (ter-cry: 0.001[?]p[?]0.01, termag: $\mathrm{p}<0.001$, luc-cry: 0.01[?]p[?]0.05, luc-mag: 0.001[?]p[?]0.01, Table 5; Figure 6). Bombus cryptarum has a significantly smaller breadth of the yellow collar at the dorsal side than B. lucorum and B. magnus (0.001[?]p[?]0.01, Table 5; Figure 6) and B. lucorum has a significantly larger breadth of the dorsal collar compared to the other three species (0.001[?]p[?]0.01, Table 5; Figure 6). However, both the intertegular distance as well as the breadth of the dorsal collar show overlap between all species. Again, B. magnus shows a significantly longer yellow collar below the tegula on both the right and left side than the other species $(\mathrm{p}<0.001$, Table 5; Figure 6), but at the lower margin there is also overlap between all three other species. When considering the breadth of the yellow collar below the tegula, B. magnus has a significantly larger breadth compared to B. terrestris on the right and left side $(\mathrm{p}<0.001$, Table 5; Figure 6$)$ and compared to B. cryptarum on the left side (0.001[?]p[?]0.01, Table 5; Figure 6). However, all the species show overlap within these characteristics.

The residual plot for males shows strong positive relations between $B$. cryptarum and melanisation of the collar and between B. lucorum and yellow facial hair (Figure 7). Bombus magnus has positive relations with both yellow hairs on the scutellum and the yellow moustache and again a negative relation with brown-yellow bands (Figure 7). Bombus terrestris males show a positive relation with brown-yellow bands (Figure 7). The presence/absence table shows something similar to the residual plot. Almost all males of $B$. lucorum possess yellow facial hair $(7 / 8)$ and almost all males of $B$. magnus show the presence of a yellow moustache $(18 / 19)$ and yellow hairs on the scutellum (17/19; Table 4$)$. Noteworthy is the high amount of $B$. terrestris males with brown-yellow bands (42/59; Table 4$)$.

According to the results from the pairwise comparisons, B. terrestris males have a significantly larger intertegular distance than the other three species $(\mathrm{p}<0.001$, Table 5 ; Figure 8$)$. Considering the breadth of the yellow collar at the dorsal side, $B$. lucorum and $B$. magnus have a significantly larger breadth than B. terrestris (luc-ter: 0.01[?]p[?]0.05, mag-ter: 0.001[?]p[?]0.01, Table 5; Figure 8). However, again these characteristics show overlap between all species. Bombus lucorum and B. magnus also have a significantly longer yellow collar below the tegula than $B$. cryptarum and $B$. terrestris on both the right and left side $(\mathrm{p}<0.001$, Table 5; Figure 8), but B. magnusshows overlap between B. cryptarum and B. terrestris at the lower margin of these characteristics. Bombus magnus has a significantly larger breadth of the yellow collar compared to the other three species on both the right $(\mathrm{p}<0.001$, Table 5; Figure 8$)$ and left side (mag-cry: $\mathrm{p}<0.001$, mag-luc: 0.001[?]p[?]0.01, mag-ter: $\mathrm{p}<0.001$, Table 5; Figure 8), but at the lower margin there is also overlap with the other three species.

\section{Discussion}

Overall, this study shows that distinction of the four white-tailed bumblebee species in the Netherlands by means of easily identifiable morphological characteristics is difficult. There is overlap in morphological traits, especially in workers and males and supports the results observed in other areas were these four species co-occur (Rasmont, 1984; Rasmont et al. 1986; Murray et al. 2008; Bertsch, 2009; Waters et al. 2011). In every combination of species and caste/sex there was at least one specimen that overlapped (in 2-dimensional space) with other species' characteristics, except for B. magnus queens. DNA sequencing was the only method that clearly separated all four species, as shown by other studies (Murray et al. 2008; Carolan et al. 2012). Not using DNA-barcoding for species identification can lead to potential errors. 
The S-shape in B. cryptarum and the collar extension in B. magnus are often mentioned as reasonably useful in queens, because they are present in most cases (Bertsch et al. 2004; Bertsch et al. 2005; Carolan et al. 2012). However, even though Carolan et al. (2012) used a larger sample size from Ireland and Denmark, they found much overlap of these two characters with the other species (Carolan et al. 2012), which is in contrast to the present study in which the S-shape was only present in B. cryptarum queens and one queen of $B$. terrestris dalmatinus (used for crop pollination in greenhouses and a non-native subspecies) and extension of the collar only present in B. magnus queens. This suggests that at least for the Netherlands these are simple and useful characteristics that can even be used in the field. The fact that queens showed the clearest separation is in concordance with Bertsch, who states that spring queens are not difficult to identify based on morphology (Bertsch et al. 2004; Bertsch et al. 2005; Bertsch 2009).

In workers, the large breadth of the collar at the dorsal side separated $B$. lucorum and the length and extension of the collar slightly separated B. magnus from the other species, which was also shown by Waters who crudely distinguished B. magnus from B. lucorum based on the length of the collar (Waters et al. 2011). However, the fact that not all specimens were correctly identified and $B$. cryptarum workers could not be separated in their study indicates the difficulty in species identification of workers of thelucorum complex. This follows the conclusion from the present study that workers of the four species do not show clear groups even if several characters and measurements are used. This is in concordance with Murray et al. (2008), who states that workers of the four species are difficult to identify based on morphology. This study also showed that workers possess great intraspecific variation, which makes morphological species identification even more difficult.

Facial hair characteristics are of significance in separating males of the four species, particularly the many yellow hairs on the face of $B$. lucorum and the presence of a yellow moustache in $B$. magnus. This is partly in line with Rasmont, who saw on average more yellow hairs on the face of $B$. lucorum compared to $B$. magnus in Belgian bumblebees (Rasmont et al. 1986) and this was also mentioned by Roland De Jonghe (R. De Jonghe personal communication). Other characters which play an important role in distinguishing B. magnus males are the presence of yellow hairs on the scutellum and the large breadth of the yellow collar. Again, this is partially in accordance with Rasmont et al. 1986. He describes that both B. lucorum and B. magnus possess yellow hairs on the scutellum, although more prominent in $B$. magnus . On the other hand, he too mentions a broad yellow collar in B. magnus. It must be said that extremely pale males of B. lucorum exists with yellow hairs on most of the thorax and abdomen (Falk, 2017). Moreover, Bombus lucorum males tend to have pale hairs in the black areas on the thorax and abdomen, which gives them a more greyish appearance (Rasmont et al. 1986; Amiet, 1996).

Bumblebees are hairy insects and for that reason, distance measurements are difficult. It is not always clear what the borders are of a particular hair patch, such as the yellow collar. Therefore, anyone using these measurements has the possibility to make mistakes, which makes them less useful as characteristics.

What is remarkable is that many studies do not describe accurately in what way the breadth and length of the collar were measured (Williams 2000; Carolan et al. 2012). Then the problem arises that measurements are done in different ways by different authors, which makes their work less comparable to each other and also less useful for researchers wishing to identify the four white-tailed species. In studies of the British Isles, B. terrestris is not included because it is easily distinguishable from the lucorum species complex based on colour pattern. However, for the Netherlands this distinction is not clear, as illustrated above. Because of this similarity, the danger often arises that the lucorum species complex together with B. terrestris is combined under the name terrestris/lucorum. The species status of B. cryptarum, B. lucorum and B. magnus is then unclear, due to the much greater abundance of $B$. terrestris .

Correct identification of species is vital for biodiversity conservation. At present, the problem is that for many species it is not known if they are present in a certain area or even constitute a separate species, because of the occurrence of morphologically similar species. Even in a well-studied area like Western-Europe, this is the case for the bumblebees Bombus cryptarum, B. lucorum, B. magnus and B. terrestris . It is likely that there are many misidentifications in natural history collections, which was demonstrated by Bertsch 
(Bertsch, 2009), and nowadays these species are often lumped together as terrestris -complex. These errors can lead to incorrect conclusions about the distribution and long-term trends of these species (Bortolus, 2008). Next, these incorrect conclusions can have serious consequences, such as the unnoticed extinction of one of these bumblebee species in the Netherlands (Bortolus, 2008). Given that most bumblebees are highly susceptible to climate warming (Marshall et al. 2018) and with rising mean temperatures in the Netherlands, this scenario can become reality. This highlights the importance of giving these species the correct name. Many bumblebees of the terrestris -complex are also often used in ecological experiments and citizen science projects. Identifying them incorrect to species level can result in different conclusions, as we know that at least B. magnus has a different ecology than the other species.

As we have shown, DNA-barcoding is the only method that clearly separates all three castes of all four species. Of course, DNA-barcoding is not feasible for everyone who wants to study the four white-tailed bumblebee species. Therefore, a recommendation was made to help with the identification of these species. The first step in the identification process is to determine the caste/sex of the individual bumblebee. If it is a queen and it has an extension of the yellow collar far below the tegula, it is B. magnus. If the queen has an S-shape line of black hairs in the yellow collar, it is B. cryptarum. If none of these characteristics are met, DNA-barcoding is the final solution. For workers we recommend the use of DNA-barcoding to identify the species.

If it is a male with a yellow moustache and yellow hairs on the scutellum, it is probably B. magnus . If a male has many yellow hairs on the face, it is most likely B. lucorum. If these characteristics are not met, DNA-barcoding is the final solution.

\section{Literature cited}

Altschul, Stephen F., Warren Gish, Webb Miller, Eugene W. Myers and David J. Lipman. 1990. "Basic Local Alignment Search Tool." Journal of molecular biology 215(3): 403-10. DOI: 10.1016/S0022-2836(05)80360-2

Amiet, F. 1996. Hymenoptera, Apidae. I. Allgemeiner Teil, Gattungsschlussel, die Gattungen Apis, Bombus und Psithyrus . - Fauna Helvetica 12: 1-98.

Banaszak, Jozef, Pierre Rasmont. 1994. "Occurrence and distribution of the subgenus Bombus Latreille sensu stricto in Poland (Hymenoptera, Apoidea)." Polskie Pismo Entomologiczne 63: 337-356

Bertsch, Andreas. 1997. "Discrimination of the Bumblebee Species Bombus Cryptarum and B. Lucorum by Means of Male Labial Gland Secretions and Morphological Characters (Hymenoptera: Apidae) [in German]." Entomologia Generalis 22(2): 129-45.

Bertsch, Andreas, Horst Schweer, Andreas Titze. 2004. "Discrimination of the bumblebee species Bombus lucorum, B. cryptarum and B. magnus by morphological characters and male labial gland secretions (Hymenoptera: Apidae)." Beitrage zur Entomologie 54(2): 365-386.

Bertsch, Andreas, Horst Schweer, Andreas Titze and H. Tanaka. 2005. "Male Labial Gland Secretions and Mitochondrial DNA Markers Support Species Status of Bombus cryptarum and B. magnus (Hymenoptera, Apidae)." Insectes Sociaux 52(1): 45-54.

Bertsch, Andreas. 2009. "Barcoding cryptic bumblebee taxa: B. lucorum, B. crytarum and B. magnus, a case study (Hymenoptera: Apidae: Bombus)." Beitrage zur Entomologie 59(2): 287-310. DOI: 10.21248/contrib.entomol.59.2.287-310

Biesmeijer, J. C., S. P. M. Roberts, M. Reemer, R. Ohlemuller, M. Edwards, T. Peeters, A. P. Schaffers, S. G. Potts, R. Kleukers, C. D. Thomas, J. Settele, W. E. Kunin. 2006. "Parallel Declines in Pollinators and Insect-Pollinated Plants in Britain and the Netherlands." Science 313(5785): 351-54. http://www.sciencemag.org/cgi/doi/10.1126/science.1127863.

Bortolus, Alejandro. 2008. "Error Cascades in the Biological Sciences: The Unwanted Consequences of Using Bad Taxonomy in Ecology," AMBIO: A Journal of the Human Environment, 37(2), 114-118. 
https://doi.org/10.1579/0044-7447(2008)37[114:ECITBS]2.0.CO;2

Bossert, Silas. 2015. "Recognition and Identification of Bumblebee Species in the Bombus Lucorum- Complex (Hymenoptera, Apidae) - A Review and Outlook." Deutsche Entomologische Zeitschrift 62(1): 19-28. http://dez.pensoft.net/articles.php?id=4786.

Bossert, Silas, Barbara-Amina Gereben-Krenn, Johann Neumayer, Bernhard Schneller and Harald W. Krenn. 2016. "The Cryptic Bombus Lucorum Complex (Hymenoptera: Apidae) in Austria: Phylogeny, Distribution, Habitat Usage and a Climatic Characterization Based on COI Sequence Data." Zoological Studies 55: 1-15. DOI:10.6620/ZS.2016.55-13

Cameron, Sydney A., Jeffrey D. Lozier, James P. Strange, Jonathan B. Koch, Nils Cordes, Leellen F. Solter and Terry L. Griswold. 2011. "Patterns of Widespread Decline in North American Bumble Bees." Proceedings of the National Academy of Sciences U.S.A. 108(2): 662-667.

Carolan, James C., Tomas E. Murray, Una Fitzpatrick, John Crossley, Hans Schmidt, Bjorn Cederberg, Luke McNally, Robert J. Paxton, Paul H. Williams and Mark J. F. Brown. 2012. "Colour Patterns Do Not Diagnose Species: Quantitative Evaluation of a DNA Barcoded Cryptic Bumblebee Complex." PLoS ONE 7(1): e29251.

Carvalheiro, Luisa Gigante, William E. Kunin, Petr Keil, Jesus Aguirre-Gutierrez, Willem Nicolaas Ellis, Richard Fox, Quentin Groom, Stephan Hennekens, Wouter Van Landuyt, Dirk Maes, Frank Van de Meutter, Denis Michez, Pierre Rasmont, Baudewijn Ode, Simon Geoffrey Potts, Menno Reemer, Stuart Paul Masson Roberts, Joop Schaminee, Michiel F. WallisDeVries and Jacobus Christiaan Biesmeijer. 2013. "Species Richness Declines and Biotic Homogenisation Have Slowed down for NW-European Pollinators and Plants." Ecology Letters 16(7): 870-78. DOI: 10.1111/ele.12121

De Jonghe, Roland, Pierre Rasmont. 1983. "Kreuzungsexperiment mit Hummeln des Genus Bombus Latreille sensu stricto (Hymenoptera, Apidae)". Phegea 11(1): 7-10.

Van Dooren, T.J.M. "Assessing species richness trends: Declines of bees and bumblebees in the Netherlands since 1945." Ecol Evol . 2019; 9: 13056-13068.

https://doi.org/10.1002/ece3.5717

Falk, Steven F. 2017. Translation: Guido, O. Keijl. Veldgids bijen voor Nederland en Vlaanderen. (c) 2017 Kosmos uitgevers, Utrecht/Antwerpen. No. pages: 432.

Folmer, Ole., Michael Black, W. Hoeh, R. Lutz and Robert Vrijenhoek. 1994. "DNA Primers for Amplification of Mitochondrial Cytochrome c Oxidase Subunit I from Diverse Metazoan Invertebrates." Molecular Marine Biology and Biotechnology 3(5): 294-99.

Geneious(r) 8.1.8 Build 2015-11-24 11:06 Java Version 1.7.0_51-b13 (64 bit) Non-commercial floating R8 license Registered to NCB Naturalis DNA Barcoding Website: www.geneious.com Support: https://support.geneious.com Created by the Biomatters development team Copyright (c) 2005-2015 Biomatters Ltd. All rights reserved.

Goulson, Dave, G.C. Lye, B. Darvill. 2008. "Decline and Conservation of Bumble Bees." Annual Review of Entomology 53(1): 191-208. DOI: 10.1146/annurev.ento.53.103106.093454

Guindon, Stephane and Olivier Gascuel. 2003. "A Simple, Fast, and Accurate Algorithm to Estimate Large Phylogenies by Maximum Likelihood." Systematic Biology 52(5): 696-704. DOI: $10.1080 / 10635150390235520$

Marshall, L., Biesmeijer, J.C., Rasmont, P., et al. "The interplay of climate and land use change affects the distribution of EU bumblebees." Glob Change Biol . 2018; 24: 101- 116. https://doi.org/10.1111/gcb.13867

Murray, Tomas E., Una Fitzpatrick, Mark J. F. Brown and Robert J. Paxton. 2008. "Cryptic Species Diversity in a Widespread Bumble Bee Complex Revealed Using Mitochondrial DNA RFLPs." Conservation 
Genetics 9(3): 653-66. DOI: 10.1007/s10592-007-9394-z

Pedersen, Bo Vest. 2002. "European Bumblebees (Hymenoptera: Bombini) - Phylogenetic Relationships Inferred from DNA Sequences." Insect Systematics \& Evolution 33(4): 361-86. DOI: $10.1163 / 187631202 \times 00208$

Peeters, T. M. J., Hans Nieuwenhuijsen, Jan Smit, Frank van der Meer, Ivo P. Raemakers, Wijnand R. B. Heitmans, Kees van Achterberg, Manja Kwak, Anne Jan Loonstra, Jeroen de Rond, Mervyn Roos and Menno Reemer. 2012. "De Nederlandse bijen (Hymenoptera: Apidae s.l.)." Natuur van Nederland 11, Naturalis Biodiversity Center \& European Invertebrate Survey. Nederland, Leiden. No. pages: 560.

R Core Team (2017). "R: A language and environment for statistical computing." R Foundation for Statistical Computing, Vienna, Austria. URL https://www.R-project.org/

Rambaut, Andrew. 2006-2016. Institute of Evolutionary Biology, University of Edinburgh. http://tree.bio.ed.ac.uk/

Rasmont, Pierre. 1984. "Les bourdons du genre Bombus Latreille sensu stricto en Europe Occidentale et Centrale (Hymenoptera, Apidae)." Spixiana 7(2):135-160.

Rasmont, Pierre, A. Scholl, R. De Jonghe, E. Obrecht, A. Adamski. 1986. "Identite et variabilite des males de bourdons du genre Bombus Latreille sensu stricto en Europe occidentale et centrale (Hymenoptera, Apidae, Bombinae)." Revue Suisse de Zoologie 93(3):661-682.

Schmidt, Stefan, Christian Schmid-egger, Jerome Moriniere, Gerhard Haszprunar and Paul D. N. Hebert. 2015. "DNA Barcoding Largely Supports 250 Years of Classical Taxonomy: Identifications for Central European Bees (Hymenoptera, Apoidea partim )." Molecular Ecology Resources 15: 985-1000. DOI: 10.1111/1755-0998.12363

Scriven, Jessica J., Lucy C. Woodall, Matthew C. Tinsley, Mairi E. Knight, Paul H. Williams, James C. Carolan, Mark J. F. Brown and Dave Goulson. 2015. "Revealing the Hidden Niches of Cryptic Bumblebees in Great Britain: Implications for Conservation." Biological Conservation 182(2015): 126-133. DOI: http://dx.doi.org/10.1016/j.biocon.2014.11.027

Scriven, Jessica J, Penelope R. Whitehorn, Dave Goulson and Matthew C. Tinsley. 2016. "Niche Partitioning in a Sympatric Cryptic Species Complex." Ecology and Evolution 6(5): 1328- 1339.

Urbanova, Klara, Irena Valterova, Oldřich Hovorka, Jiří Kindl. 2001. "Chemotaxonomical characterisation of males of Bombus lucorum (Hymenoptera: Apidae) collected in the Czech Republic." European Journal of Entomology 98(1):111-115.

Velthuis, Hayo H. W. and Adriaan Van Doorn. 2006. "A Century of Advances in Bumblebee Domestication and the Economic and Environmental Aspects of Its Commercialization for Pollination." Apidologie 37(2006): 421-51. DOI: 10.1051/apido:2006019

Vesterlund, S.-R., J. Sorvari and A. Vasemägi. 2014. "Molecular Identification of Cryptic Bumblebee Species from Degraded Samples Using PCR-RFLP Approach." Molecular Ecology Resources 14(1): 122-26. DOI: 10.1111/1755-0998.12168

Waters, Joe, Ben Darvill, Gillian C. Lye and Dave Goulson. 2011. "Niche Differentiation of a Cryptic Bumblebee Complex in the Western Isles of Scotland." Insect Conservation and Diversity 4(1): 46-52. DOI: 10.1111/j.1752-4598.2010.00101.x

Williams, Paul H. 2000. "Are Bombus lucorum and magnus separate species?" BWARS Newsletter 2000(1): $15-17$.

Williams, Paul H., Jiandong An, Mark J. F. Brown, James C. Carolan, Dave Goulson, Jiaxing 
Huang and Masao Ito. 2012. "Cryptic Bumblebee Species: Consequences for Conservation and the Trade in Greenhouse Pollinators." PLoS ONE 7(3): 1-8.

Tables

Table 1. Sample sites and number of specimens per site. Five individual bumblebees were added by John Smit from Dwingelderveld.

\begin{tabular}{llll}
\hline Sample site & Number of sampling days & Dates (2017) & Number of specimens \\
\hline Dwingelderveld & 1 & $26-07$ & 25 \\
Kalmthoutse heide (BE) & 1 & $24-08$ & 25 \\
Lunterse bos & 2 & $24-05,14-06$ & 7 \\
Meijendel & 2 & $04-04,31-05$ & 31 \\
Slikken van de Heen & 1 & $24-08$ & 20 \\
Terschelling & 6 & $09 / 11-05,02 / 04-08$ & 66 \\
Tiengemeten & 1 & $26-05$ & 29 \\
Vliegbasis Soesterberg & 2 & $16-05,26-06$ & 37 \\
Wijlre, Zuid-Limburg & 1 & $13-07$ & 20 \\
Zuid-Kennemerland & 2 & $08-05,18-07$ & 37 \\
& & & $\mathbf{2 9 7}$ \\
\hline
\end{tabular}

Table 2. Additional specimens

\begin{tabular}{ll}
\hline Specimens from & Number of specimens \\
\hline Koppert Biological systems & 2 \\
Roland De Jonghe (self-bred) & 152 \\
& $\mathbf{1 5 4}$ \\
\hline
\end{tabular}

Table 3. Overview male characteristics used by Rasmont (Rasmont et al. 1986)

\begin{tabular}{llc}
\hline & B. cryptarum & B. lucoru \\
\hline Facial hair & Black hairs on face, on vertex few light hairs. Sometimes light hairs on both sides of clypeus & Light hai \\
Yellow collar & Collar below tegula, longer than terrestris & Collar ex \\
Thorax colour & Few yellow hairs on scutellum, but this is rare. Rest of thorax black & Always \\
Abdomen colour & Tergite 1 with few yellow hairs in centre & Tergite 1 \\
\hline
\end{tabular}

Table 4. Presence/absence of qualitative characteristics in queens, workers and males.

\begin{tabular}{lllllllllll}
\hline & Queens & Queens & Queens & Queens & Workers & Workers & Workers & Workers & Males & Males \\
\hline & cry. & luc. & mag. & ter. & cry. & luc. & mag. & ter. & cry. & luc. \\
S-shape & $11 / 12$ & $0 / 10$ & $0 / 4$ & $1 / 13$ & $3 / 10$ & $0 / 11$ & $0 / 41$ & $9 / 139$ & $0 / 11$ & $0 / 8$ \\
Melanisation & $2 / 12$ & $0 / 10$ & $0 / 4$ & $1 / 13$ & $1 / 10$ & $0 / 11$ & $0 / 41$ & $2 / 139$ & $5 / 11$ & $0 / 8$ \\
Extension & $0 / 12$ & $0 / 10$ & $4 / 4$ & $0 / 13$ & $0 / 10$ & $0 / 11$ & $25 / 41$ & $5 / 139$ & $6 / 11$ & $8 / 8$ \\
Brown-yellow bands & $8 / 12$ & $9 / 10$ & $0 / 4$ & $13 / 13$ & $4 / 10$ & $6 / 11$ & $3 / 41$ & $95 / 139$ & $2 / 11$ & $0 / 8$ \\
Yellow moustache & $0 / 12$ & $0 / 10$ & $0 / 4$ & $0 / 13$ & $0 / 10$ & $0 / 11$ & $0 / 41$ & $0 / 139$ & $1 / 11$ & $1 / 8$ \\
Yellow facial hair & $0 / 12$ & $0 / 10$ & $0 / 4$ & $0 / 13$ & $0 / 10$ & $0 / 11$ & $0 / 41$ & $0 / 139$ & $0 / 11$ & $7 / 8$ \\
Yellow hair scutellum & $0 / 12$ & $0 / 10$ & $0 / 4$ & $0 / 13$ & $0 / 10$ & $0 / 11$ & $0 / 41$ & $0 / 139$ & $0 / 11$ & $1 / 8$ \\
\hline
\end{tabular}


Table 5. Results from the pairwise comparisons of the quantitative characteristics. Significance level: $\mathrm{p}>0.05=$ non-significant $(\mathrm{NS}), 0.01[?] \mathrm{p}[?] 0.05=^{*}, 0.001[?] \mathrm{p}[?] 0.01=* *$ and $\mathrm{p}<0.001=* * *$

\begin{tabular}{|c|c|c|c|}
\hline Comparison & Character & Caste/sex & $\overline{\text { Significance }}$ \\
\hline lucorum-cryptarum & intertegular distance & queen & $\mathrm{NS}$ \\
\hline magnus-cryptarum & intertegular distance & queen & NS \\
\hline terrestris-cryptarum & intertegular distance & queen & $* *$ \\
\hline magnus-lucorum & intertegular distance & queen & $\mathrm{NS}$ \\
\hline terrestris-lucorum & intertegular distance & queen & NS \\
\hline terrestris-magnus & intertegular distance & queen & $\mathrm{NS}$ \\
\hline lucorum-cryptarum & collar breadth & queen & $* * *$ \\
\hline magnus-cryptarum & collar breadth & queen & $* * *$ \\
\hline terrestris-cryptarum & collar breadth & queen & $* * *$ \\
\hline magnus-lucorum & collar breadth & queen & NS \\
\hline terrestris-lucorum & collar breadth & queen & NS \\
\hline terrestris-magnus & collar breadth & queen & NS \\
\hline lucorum-cryptarum & length collar right & queen & NS \\
\hline magnus-cryptarum & length collar right & queen & $* * *$ \\
\hline terrestris-cryptarum & length collar right & queen & NS \\
\hline magnus-lucorum & length collar right & queen & $* * *$ \\
\hline terrestris-lucorum & length collar right & queen & NS \\
\hline terrestris-magnus & length collar right & queen & $* * *$ \\
\hline lucorum-cryptarum & breadth collar right & queen & NS \\
\hline magnus-cryptarum & breadth collar right & queen & NS \\
\hline terrestris-cryptarum & breadth collar right & queen & NS \\
\hline magnus-lucorum & breadth collar right & queen & NS \\
\hline terrestris-lucorum & breadth collar right & queen & NS \\
\hline terrestris-magnus & breadth collar right & queen & $\mathrm{NS}$ \\
\hline lucorum-cryptarum & length collar left & queen & NS \\
\hline magnus-cryptarum & length collar left & queen & $* * *$ \\
\hline terrestris-cryptarum & length collar left & queen & NS \\
\hline magnus-lucorum & length collar left & queen & $* * *$ \\
\hline terrestris-lucorum & length collar left & queen & NS \\
\hline terrestris-magnus & length collar left & queen & $* * *$ \\
\hline lucorum-cryptarum & breadth collar left & queen & NS \\
\hline magnus-cryptarum & breadth collar left & queen & NS \\
\hline terrestris-cryptarum & breadth collar left & queen & NS \\
\hline magnus-lucorum & breadth collar left & queen & NS \\
\hline terrestris-lucorum & breadth collar left & queen & NS \\
\hline terrestris-magnus & breadth collar left & queen & $\mathrm{NS}$ \\
\hline lucorum-cryptarum & intertegular distance & worker & $*$ \\
\hline magnus-cryptarum & intertegular distance & worker & NS \\
\hline terrestris-cryptarum & intertegular distance & worker & $* *$ \\
\hline magnus-lucorum & intertegular distance & worker & $* *$ \\
\hline terrestris-lucorum & intertegular distance & worker & $\mathrm{NS}$ \\
\hline terrestris-magnus & intertegular distance & worker & $* * *$ \\
\hline lucorum-cryptarum & collar breadth & worker & $* *$ \\
\hline magnus-cryptarum & collar breadth & worker & $* *$ \\
\hline terrestris-cryptarum & collar breadth & worker & NS \\
\hline magnus-lucorum & collar breadth & worker & $* *$ \\
\hline terrestris-lucorum & collar breadth & worker & $* *$ \\
\hline
\end{tabular}




\begin{tabular}{|c|c|c|c|}
\hline Comparison & Character & Caste/sex & Significance \\
\hline terrestris-magnus & collar breadth & worker & * \\
\hline lucorum-cryptarum & length collar right & worker & NS \\
\hline magnus-cryptarum & length collar right & worker & $* * *$ \\
\hline terrestris-cryptarum & length collar right & worker & NS \\
\hline magnus-lucorum & length collar right & worker & $* * *$ \\
\hline terrestris-lucorum & length collar right & worker & NS \\
\hline terrestris-magnus & length collar right & worker & $* * *$ \\
\hline lucorum-cryptarum & breadth collar right & worker & NS \\
\hline magnus-cryptarum & breadth collar right & worker & NS \\
\hline terrestris-cryptarum & breadth collar right & worker & NS \\
\hline magnus-lucorum & breadth collar right & worker & NS \\
\hline terrestris-lucorum & breadth collar right & worker & $\mathrm{NS}$ \\
\hline terrestris-magnus & breadth collar right & worker & $* * *$ \\
\hline lucorum-cryptarum & length collar left & worker & NS \\
\hline magnus-cryptarum & length collar left & worker & $* * *$ \\
\hline terrestris-cryptarum & length collar left & worker & NS \\
\hline magnus-lucorum & length collar left & worker & $* * *$ \\
\hline terrestris-lucorum & length collar left & worker & NS \\
\hline terrestris-magnus & length collar left & worker & $* * *$ \\
\hline lucorum-cryptarum & breadth collar left & worker & NS \\
\hline magnus-cryptarum & breadth collar left & worker & $* *$ \\
\hline terrestris-cryptarum & breadth collar left & worker & NS \\
\hline magnus-lucorum & breadth collar left & worker & NS \\
\hline terrestris-lucorum & breadth collar left & worker & $\mathrm{NS}$ \\
\hline terrestris-magnus & breadth collar left & worker & $* * *$ \\
\hline lucorum-cryptarum & intertegular distance & males & NS \\
\hline magnus-cryptarum & intertegular distance & males & $\mathrm{NS}$ \\
\hline terrestris-cryptarum & intertegular distance & males & $* * *$ \\
\hline magnus-lucorum & intertegular distance & males & $\mathrm{NS}$ \\
\hline terrestris-lucorum & intertegular distance & males & $* * *$ \\
\hline terrestris-magnus & intertegular distance & males & $* * *$ \\
\hline lucorum-cryptarum & collar breadth & males & NS \\
\hline magnus-cryptarum & collar breadth & males & NS \\
\hline terrestris-cryptarum & collar breadth & males & $\mathrm{NS}$ \\
\hline magnus-lucorum & collar breadth & males & NS \\
\hline terrestris-lucorum & collar breadth & males & $*$ \\
\hline terrestris-magnus & collar breadth & males & $* *$ \\
\hline lucorum-cryptarum & length collar right & males & $* * *$ \\
\hline magnus-cryptarum & length collar right & males & $* * *$ \\
\hline terrestris-cryptarum & length collar right & males & NS \\
\hline magnus-lucorum & length collar right & males & NS \\
\hline terrestris-lucorum & length collar right & males & $* * *$ \\
\hline terrestris-magnus & length collar right & males & $* * *$ \\
\hline lucorum-cryptarum & breadth collar right & males & $\mathrm{NS}$ \\
\hline magnus-cryptarum & breadth collar right & males & $* * *$ \\
\hline terrestris-cryptarum & breadth collar right & males & NS \\
\hline magnus-lucorum & breadth collar right & males & $* * *$ \\
\hline terrestris-lucorum & breadth collar right & males & NS \\
\hline terrestris-magnus & breadth collar right & males & $* * *$ \\
\hline lucorum-cryptarum & length collar left & males & $* * *$ \\
\hline
\end{tabular}




\begin{tabular}{llll}
\hline Comparison & Character & Caste/sex & Significance \\
\hline magnus-cryptarum & length collar left & males & $* * *$ \\
terrestris-cryptarum & length collar left & males & NS \\
magnus-lucorum & length collar left & males & NS \\
terrestris-lucorum & length collar left & males & $* * *$ \\
terrestris-magnus & length collar left & males & $* * *$ \\
lucorum-cryptarum & breadth collar left & males & NS \\
magnus-cryptarum & breadth collar left & males & $* * *$ \\
terrestris-cryptarum & breadth collar left & males & NS \\
magnus-lucorum & breadth collar left & males & $* *$ \\
terrestris-lucorum & breadth collar left & males & NS \\
terrestris-magnus & breadth collar left & males & $* * *$ \\
\hline
\end{tabular}

Figure legends

Figure 1. Qualitative characters used in colour pattern analysis. Abbreviations of variables are in brackets. With (A) S-shape right and left (ssr, ssl; white arrow; Bombus cryptarum queen), (B) melanisation of the collar (mc; Bombus cryptarum queen), (C) extension of the collar right and left (ecr, ecl; white arrow;Bombus magnus queen), (D) brown-yellow bands (byb; Bombus terrestris queen) and (F) yellow hairs on the scutellum (yhs; white arrow; Bombus magnus male).

Figure 2. Qualitative characters and distances measured for colour pattern analysis. Abbreviations of variables are in brackets. With (A) black facial hairs (Bombus terrestris male, (B) yellow facial hairs (yh; Bombus lucorum male), (C) yellow moustache (ym; white arrow; Bombus magnus male), (D) intertegular distance (itd;Bombus terrestris queen) and collar breadth dorsal side (cb;Bombus terrestris queen), (E) length of collar and breadth of collar below tegula right (lcr, bcr; Bombus terrestris male) and (F) length of collar and breadth of collar below tegula left (lcl, bcl;Bombus terrestris male).

Figure 3. Residual plot showing the relationship of the qualitative characteristics and queens of B. cryptarum, B. lucorum, B. magnus and B. terrestris. Byb: brown-yellow bands, Extension: extension of the collar, Melanisation: melanisation of the collar and S-shape: S-shape line of black hairs in the collar.

Figure 4. Boxplots showing the variation in the quantitative characteristics for queens. The significant stars are the results of the pairwise comparisons. With A) intertegular distance, B) collar breadth, C) length of collar right, D) length of collar left, E) breadth of collar right and F) breadth of collar left.

Figure 5. Residual plot showing the relationship of the qualitative characteristics and workers of B. cryptarum, B. lucorum, B. magnus and B. terrestris. Byb: brown-yellow bands, Extension: extension of the collar, Melanisation: melanisation of the collar and S-shape: S-shape line of black hairs in the collar.

Figure 6. Boxplots showing the variation in the quantitative characteristics for workers. The significant stars are the results of the pairwise comparisons. With A) intertegular distance, B) collar breadth, C) length of collar right, D) length of collar left, E) breadth of collar right and F) breadth of collar left.

Figure 7. Residual plot showing the relationship of the qualitative characteristics and males of B. cryptarum, B. lucorum, B. magnus and B. terrestris. Yh: yellow hairs on the face, Yhs: yellow hairs on the scutellum and Ym: yellow moustache.

Figure 8. Boxplots showing the variation in the quantitative characteristics for males. The significant stars are the results of the pairwise comparisons. With A) intertegular distance, B) collar breadth, C) length of collar right, D) length of collar left, E) breadth of collar right and F) breadth of collar left.

Data accessibility statement 
DNA-sequences will be uploaded to Genbank once our manuscript has been accepted to Ecology and Evolution. Species coordinates have been transferred to the EIS database (http://www.eis-nederland.nl), which will be uploaded to www.waarneming.nl. Species coordinates will also be uploaded to Dryad once our manuscript has been accepted to Ecology and Evolution.

\section{Competing interests' statement}

None declared.

\section{Author contributions}

L.A., K.B. and L.M. conceived and designed the project. L.A. conducted the DNA-barcoding. All authors carried out fieldwork and supplied specimens. L.A. and L.M. conducted the statistical analyses. L.A. took the lead in writing the manuscript. All authors provided critical feedback and helped shape the research, analysis and manuscript.

\section{Acknowledgements}

We would like to thank Roland Butt and Frank Stokvis of the Naturalis DNA barcoding facility for helping with the DNA sequencing workflow; to John T. Smit for providing his bumblebee specimens and Lisette van Kolfschotten for help with the fieldwork. We would also like to thank Werner de Gier for helping with data visualizations.

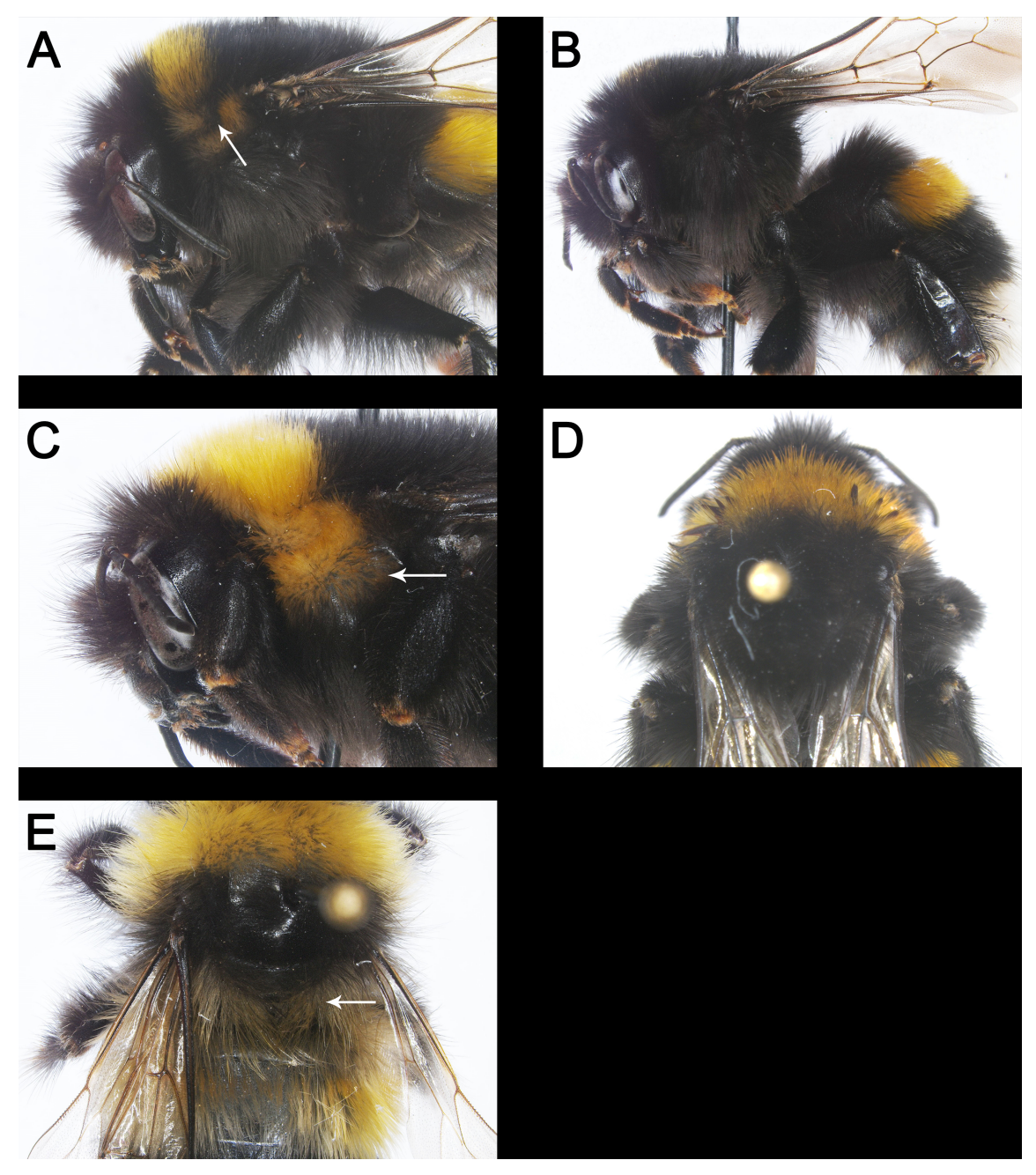



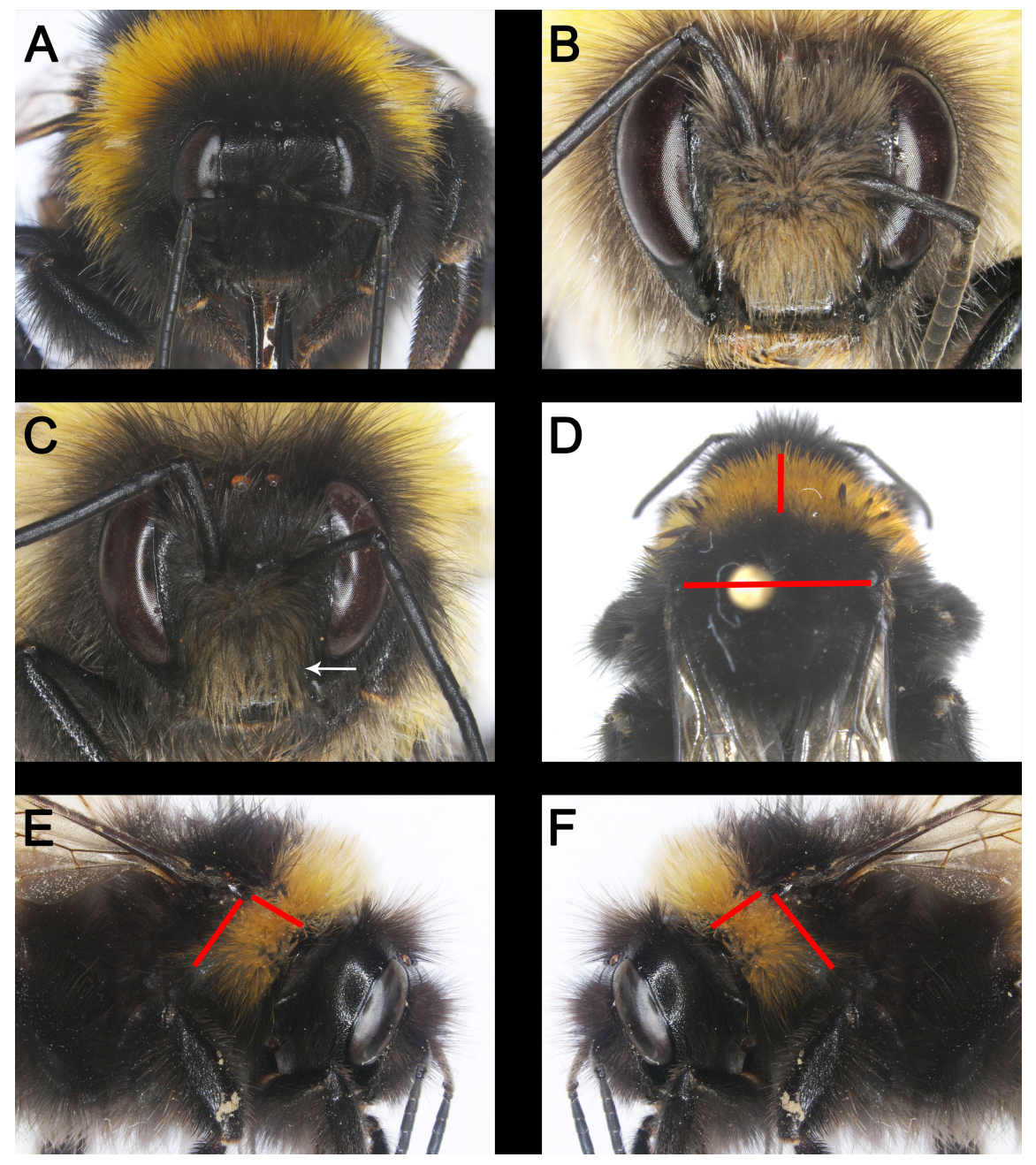


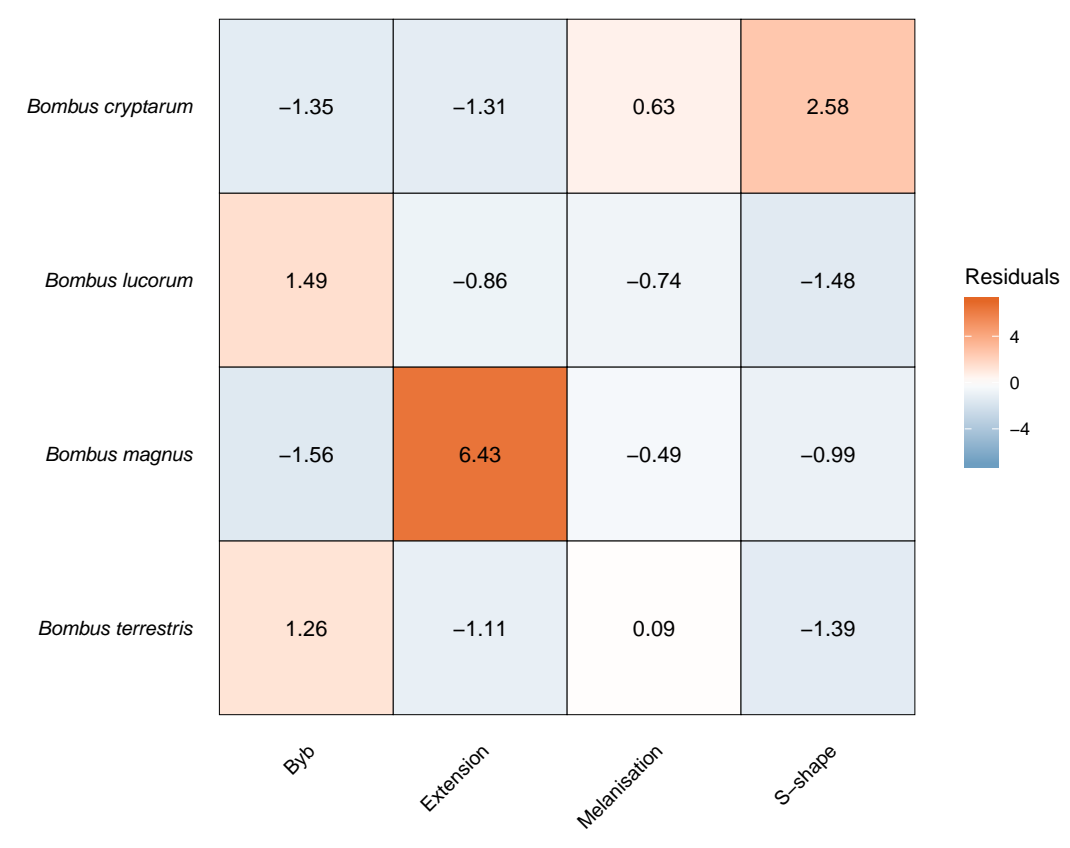



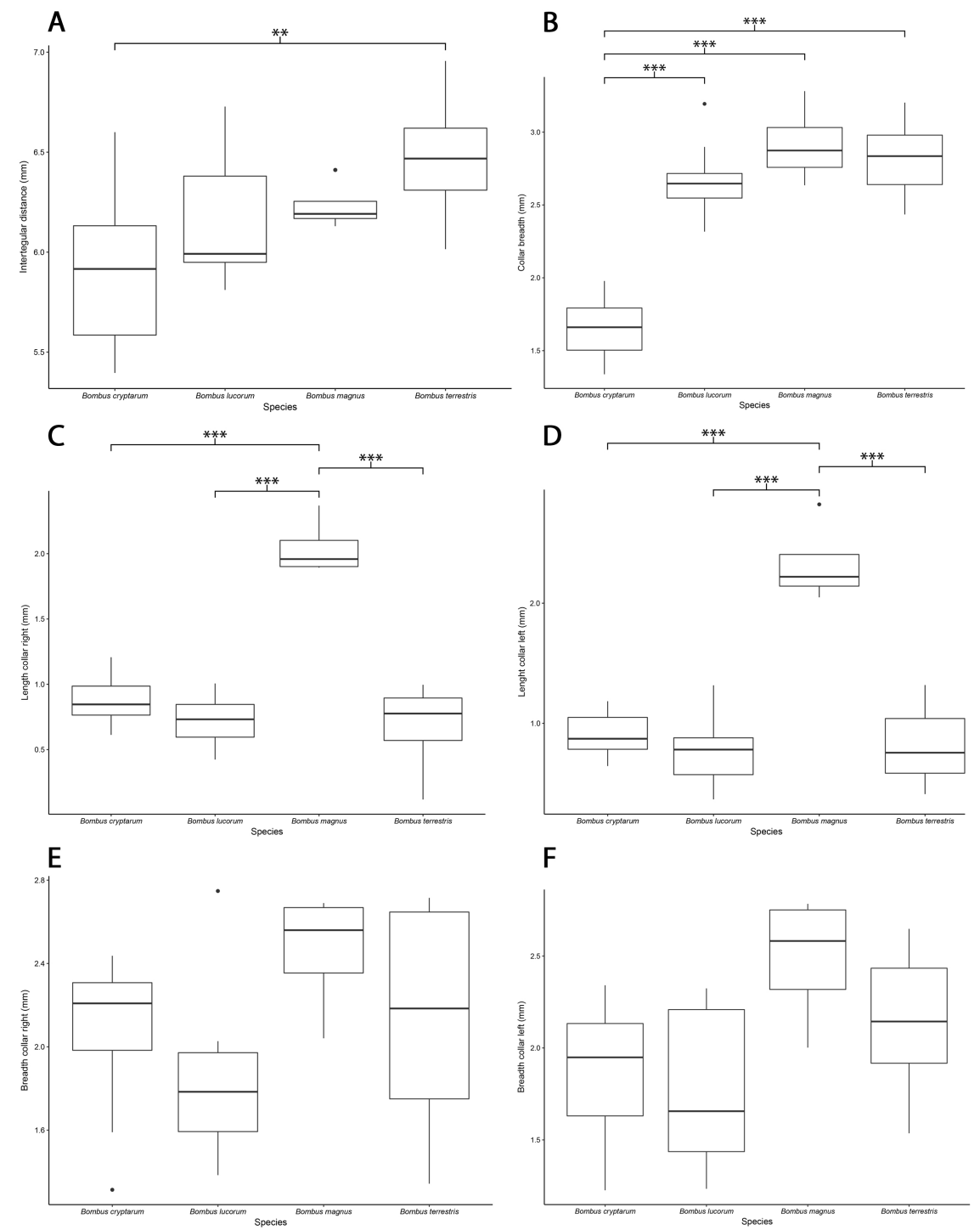


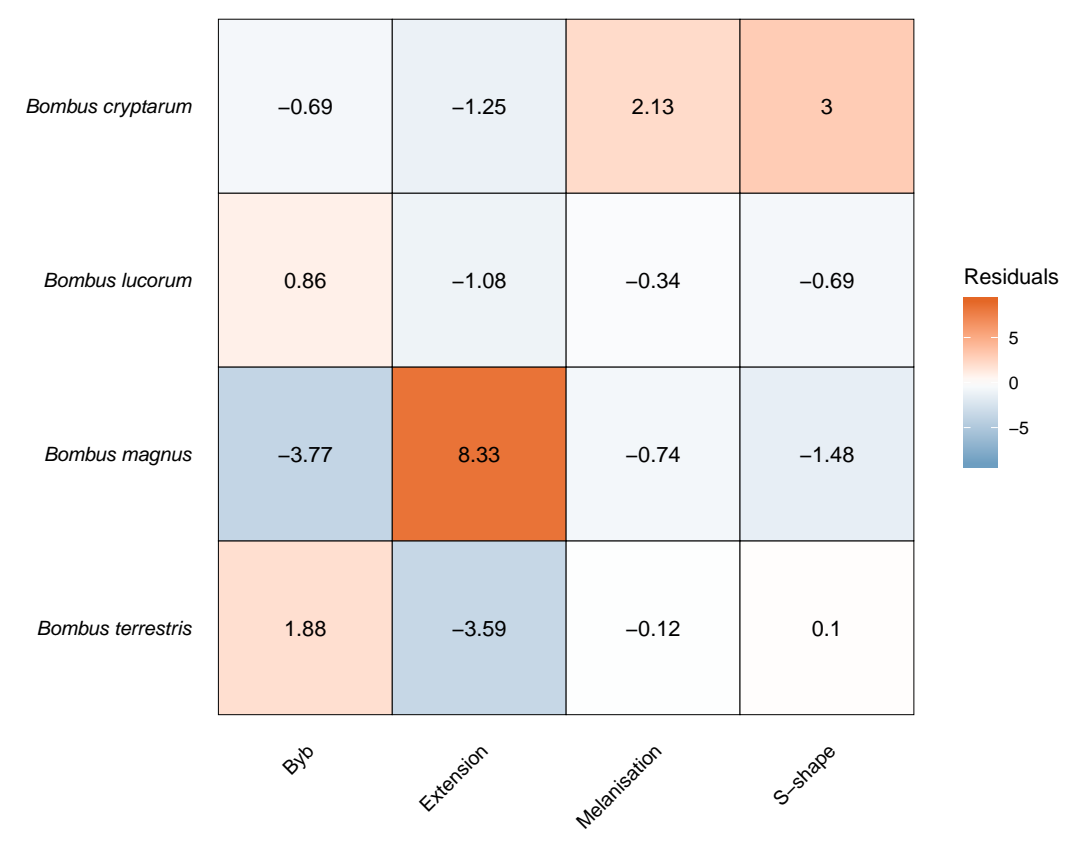



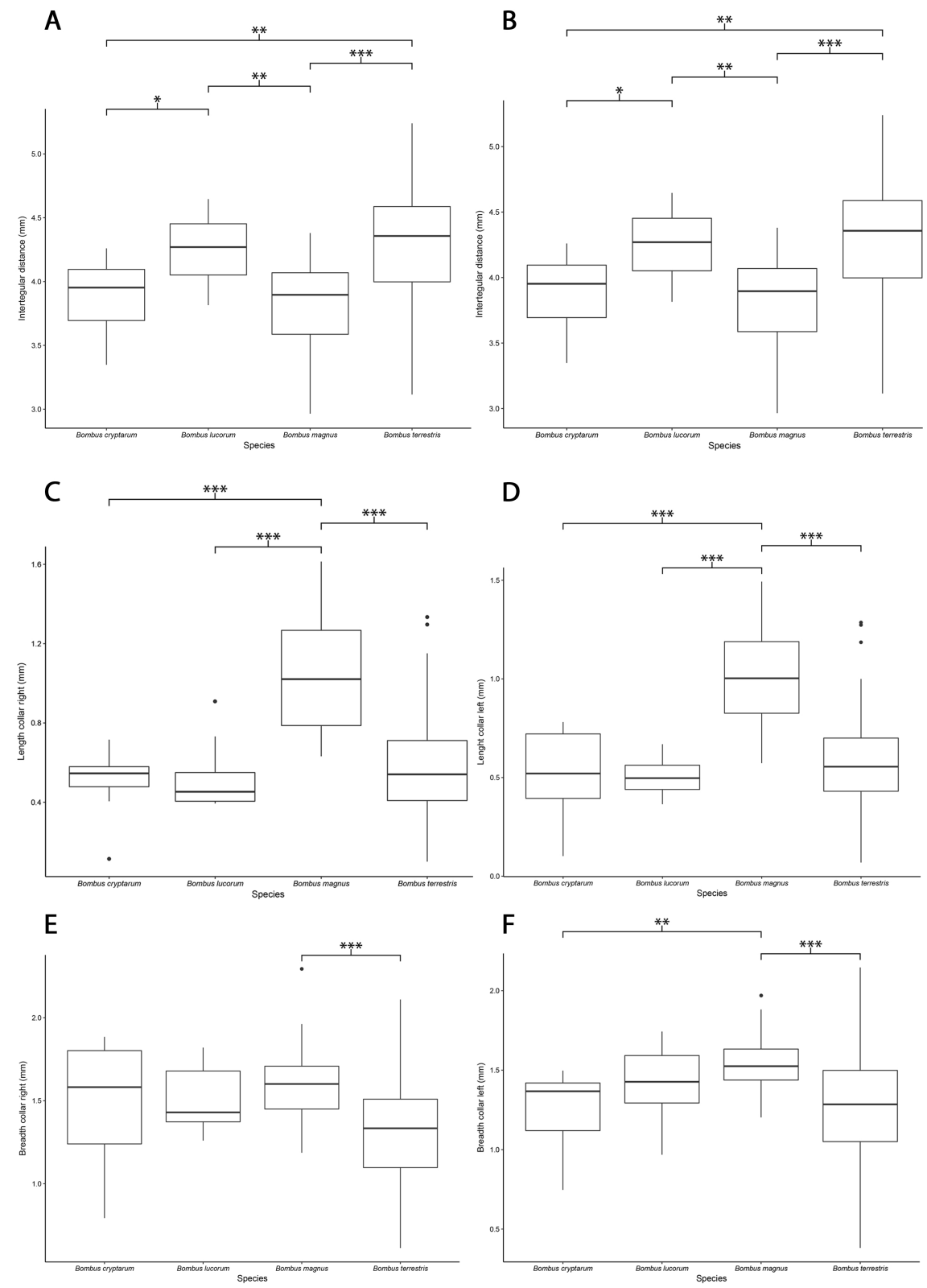


\begin{tabular}{|c|c|c|c|c|c|c|c|c|}
\hline Bombus cryptarum & -0.91 & 0.27 & 6.27 & -0.58 & -0.83 & -1.27 & -0.54 & \multirow{5}{*}{$\begin{array}{l}\text { Residuals } \\
\begin{array}{c}4 \\
0 \\
-4\end{array}\end{array}$} \\
\hline Bombus lucorum & -2.14 & 0.58 & -0.79 & -0.64 & 6.78 & -0.69 & -0.75 & \\
\hline Bombus magnus & -3.88 & -0.54 & -1.43 & -1.17 & -1.05 & 4.52 & 4.27 & \\
\hline Bombus terrestris & 4.7 & 0.08 & -1.08 & 1.55 & -1.94 & -2.99 & -3.06 & \\
\hline & s) & & & & $a^{n}$ & $n^{n^{5}}$ & tr & \\
\hline
\end{tabular}



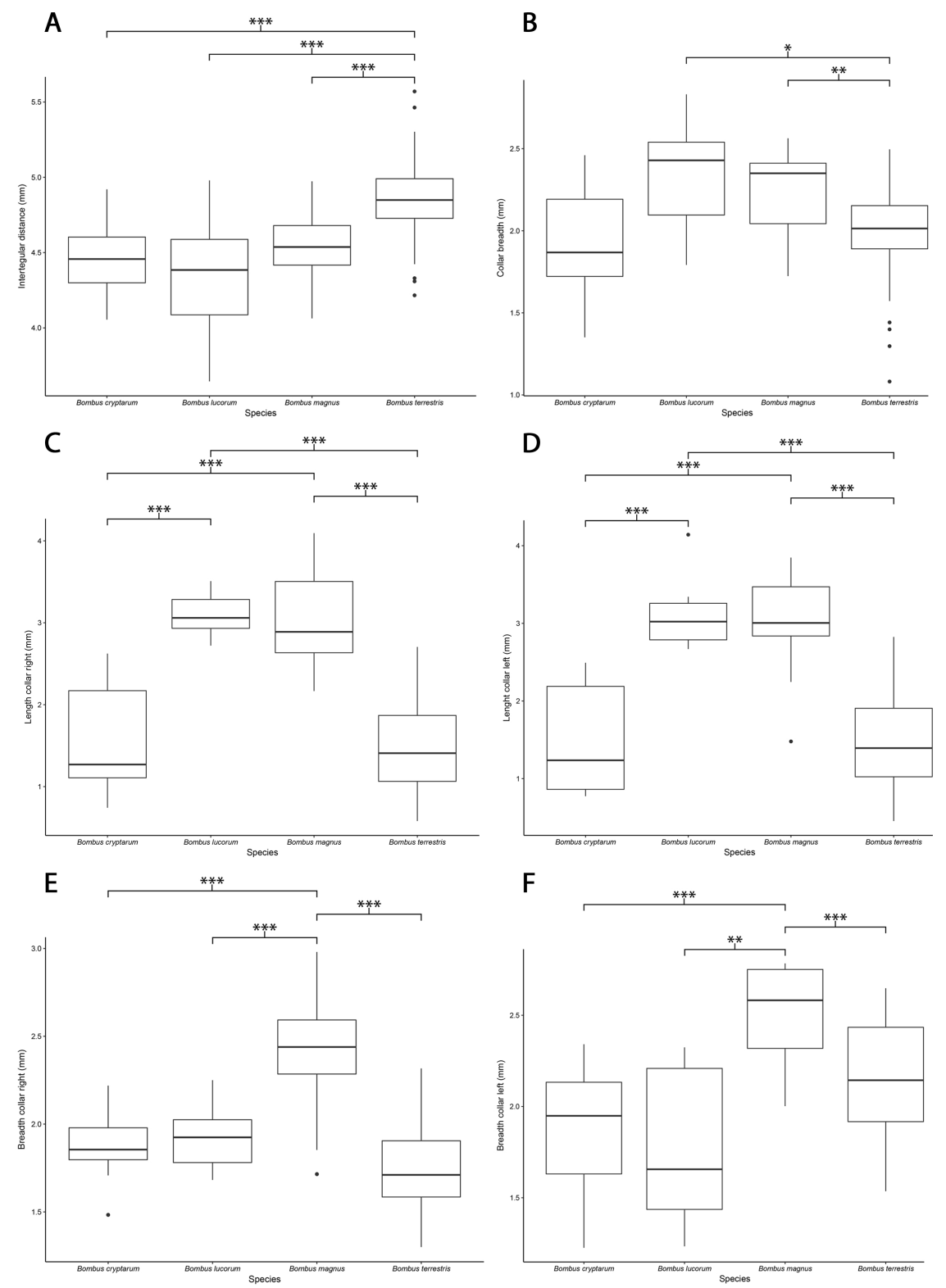